\title{
TESTIMONIOS EN TRIÁNGULO: PERSONAJES DE LA NUEVA CORÓNICA DE GUAMAN POMA Y DEL MANUSCRITO QUECHUA DE HUAROCHIRÍ EN EL PLEITO SOBRE EL CACICAZGO PRINCIPAL DE MAMA (1588-1590)
}

\author{
TRIANGULAR TESTIMONY: \\ INDIVIDUALS FROM GUAMAN POMA'S NUEVA CORÓNICA AND FROM THE \\ QUECHUA MANUSCRIPT OF HUAROCHIRI IN A LAWSUIT OVER THE \\ CACICAZGO PRINCIPAL OF MAMA (1588-1590)
}

Frank Salomon*

El extenso "Segundo pleito entre Antonio Guamanyanac y Geronimo Caxayauri 1588" (AGN/ Buenos Aires 9-45-5-15), estudiado por Espinoza Soriano (1983-84), arroja luz sobre las fricciones entre dos kurakazgos de la cuenca del río Rímac antes, durante y después de la invasión española. El presente ensayo propone que dos hermanos, ambos kurakas y maestros de khipu (khipukamayuq) que figuran en dicho pleito, a saber Condorchagua y Pomachagua de Yaucha (reducción de Huánchor), son las mismas personas Condor Chaua y Poma Chaua, dibujados por Guaman Poma, en la Nueva Corónica, como khipukamayuq imperiales del Tawantinsuyu. Enfocamos adicionalmente a la persona de D. Gerónimo Cancho Guaman, testigo en el pleito de 1588, que identificamos con el viejo kuraka de San Damián cuyas "idolatrías” figuran en el capítulo 20 del manuscrito anónimo quechua de Huarochirí ([1608?] Taylor 1987). El pleito forma un lugar común entre dos fuentes principales de la tradición etnohistórica. En ambos casos, el pleito aclara intereses y prácticas de la élite kurakal hasta ahora poco claros debido al contenido ideológico de estas dos obras narrativas, centrales de la etnohistoria andina.

Palabras claves: Etnohistoria, Andes Centrales, Perú, valle del Rímac, Inka, khipu, Huarochirí, Guaman Poma.

The extensive "Second lawsuit between Antonio Guamanyanac and Geronimo Caxayauri 1588" (AGN/Buenos Aires 9-45-5-15), studied by Espinoza Soriano (1983-84), throws light on friction between two kurakazgos of the Rímac River basin before, during, and after the Spanish invasion. This essay proposes that two brothers who figure in the lawsuit, both of them khipukamayuq (khipu masters) and kurakas, namely, Condorchagua and Pomachagua of Yaucha (resettlement of Huánchor), are the same persons as the Condor Chaua and Poma Chaua whom Guaman Poma drew as imperial khipukamayuq of Tawantinsuyu. This essay also focuses on D. Gerónimo Cancho Guaman, a witness in the 1588 lawsuit. He is the same person as the old kuraka of San Damián whose "idolatries" figure in chapter 20 of the anonymous Quechua manuscript of Huarochiri ([1608?] Taylor 1987). The lawsuit thus forms common ground between two main sources of Andean ethnohistorical tradition. The lawsuit clarifies interests and practices of the kuraka elite which have until now been overshadowed by the narrative works' ideological content.

Key words: Ethnohistory, Central Andes, Peru, Rimac valley, Inka, khipu, Huarochirí, Guaman Poma.

Espinoza Soriano (1983-84) ha analizado con lujo de detalle el intrincado litigio fichado como "Pleito segundo entre Antonio Guamanyanac y Geronimo Caxayauri 1588", existente en el Archivo General de la Nación, Buenos Aires (ms. 9-455-15). Según Espinoza Soriano, el litigio de 15881590 y sus secuelas hasta 1599 representan las etapas avanzadas de un arraigado conflicto entre dos kurakazgos importantes del valle del río Rímac: el señorío o waranka Inka de Yaucha, con sede colonial en la reducción de San Mateo de Huánchor y el señorío o waranka de Picoy, residente en S. Jerónimo de Surco e históricamente afiliado al importante centro yunka cuya reducción se llamó San Pedro de Mama (actual Ricardo Palma). La fuente no aclara la relación entre Picoy de la cuenca del Rímac y su homónimo ubicado en la actual Provincia de Oyón. La reducción serrana de Huánchor, situada a $3.140 \mathrm{msm}$, centralizó lo que en tiempos inkas había sido un extenso dominio cuyas perte-

\footnotetext{
* Department of Anthropology, University of Wisconsin, 5240 Social Science, 1180 Observatory Drive, Madison, Wisconsin 53706-1393 EE.UU. fsalomon@wisc.edu
} 
nencias incluían uno o más enclaves en las tierras subtropicales cerca de Mama y adicionalmente un extenso "archipiélago vertical" adquirido por patrocinio del Inka Tupaq Inka Yupanki. Huánchor formó parte de Huarochirí, el más poblado de los tres repartimientos que formaban la provincia colonial de Lurin Yauyos. El litigante D. Jerónimo Caxayauri representó a Yaucha de Huánchor, pretendiendo un "cacicazgo principal" con dominio sobre Picoy.

La reducción de San Pedro de Mama, en cambio, se sitúa en tierras vallunas, apenas a siete leguas de Lima en el Rímac medio. Sus habitantes originales fueron gente étnicamente yunka. Antes de las reducciones impuestas a partir de la década 1570, Picoy fue uno de los 24 ayllus de Mama, que según Espinoza Soriano (1983-84:176), se distribuían a lo largo del Rímac medio en tierras de Surco y aguas arriba hasta Matucana $(2.336 \mathrm{msm})$. El litigante D. Antonio Guamanyanac abogó tenazmente, pero al final sin éxito, por los derechos de Picoy como señorío independiente de los Yaucha de Huánchor, repudiando el supuesto "cacicazgo principal" serrano. El tercer repartimiento, Chaclla, figura pasivamente en la contienda.

El lector que desee seguir la actuación histórica de las partes, encontrará en la citada obra de Espinoza Soriano un análisis diacrónico doble, que resume tanto la larga cronología del conflicto como la cronología inmediata del pleito. Evitando repeticiones innecesarias, nos limitamos a precisar las principales etapas durante las cuales se produjeron las interacciones entre los kurakas que serán objeto del presente ensayo. En tiempos preinkas cada uno de los dos "señoríos" se constituía de múltiples ayllus, confederados bajo el mando de un linaje cuyo liderazgo pasaba por herencia fraterna antes de pasar a la generación siguiente; la sucesión por lo tanto se enredó en ramificados árboles genealógicos, cuya averiguación por los españoles motivó la exposición etnohistórica por parte de los testigos. Los kurakas de Yaucha, como los de otros "señoríos" tildados con el gentilicio "yauyo", adoptaron posturas proinkas. Su kuraka Carguayauri fue favorecido por amplios dones de terrenos en "archipiélago". El hijo de Carguayauri, Pomachagua, militó entre las huestes inkas que combatieron en las fronteras norteñas de lo que hoy es Ecuador. Mientras el Tawantinsuyu otorgó a Yaucha un amplio privilegio extendido dentro del área yunka, durante el incario el kuraka yunka de Picoy tuvo mando solamente a nivel de waranka.

La contienda colonial radicó, en que ciertos kurakas de Yaucha pretendieron utilizar la turbulencia política de los años 1532-1548, para transformar su privilegio entre los yunkas, en privilegio sobre los yunkas. Lograron imponer tal hegemonía gracias a una alianza precoz con los españoles invasores. Los personajes cruciales en este ensayo, los hermanos yauchas Pomachagua y Condorchagua, fueron protagonistas de esta alianza. Su linaje resultó beneficiario de la creación del supuesto "cacicazgo mayor" bajo la encomienda primitiva de Juan Fernández. Pomachagua y Condorchagua, como otros nobles, ayudaron a los españoles durante el cerco inka de Lima. La época toledana de las reducciones, intervención que peligraba toda tenencia de tierras en padrón de "archipiélago", también vio las etapas avanzadas de la despoblación yunka y por lo tanto impuso una desventaja adicional en Picoy frente a los serranos. Desesperado por los desastres acumulados, Picoy pretendió sin éxito recuperar su antiguo derecho y repudió el "cacicazgo mayor" espurio que los subordinó a Yaucha. Los kurakas de la vecina región de Huarochirí central apoyaron a la parte Picoy, porque Picoy, tradicional contraparte en la explotación "multiétnica" de los cocales, prometía proteger mejor los enclaves o "islas" serranas dentro de la zona chawpi yunka en el Rímac medio.

El litigio posee gran valor como panorama de la evolución inka y colonial de los kurakazgos, debido a su profundidad cronológica, que se remonta a cuatro generaciones anteriores a la conquista española, a la vivamente recordada participación de los respectivos señoríos en los eventos claves de la década 1530, y al cruce de testimonios desde varios ángulos de la constelación toledana. Como en el caso de los conflictos sobre cocales en Quivi, analizado por Rostworowski y Marcus (1988), este litigio permite seguir la transformación de un conflicto yunka-serrano en factor dentro de la política inka y posteriormente en la lucha para adquirir y utilizar las palancas del naciente poder colonial. A través de sus páginas, se traslucen las etapas sucesivas de la invasión española, cerco y resistencia, la fluida reorganización postinka de los kurakazgos, su burocratización y reducción toledanas y el colapso demográfico de los yunkas. 
El propósito de este ensayo es agregar al minucioso análisis histórico de Espinoza Soriano, la observación que el litigio Picoy-Yaucha se encuentra en relación triangular con dos fuentes centrales a la etnohistoria: la Nueva Corónica de Felipe Guaman Poma de Ayala ([1613] 1980) y el manuscrito anónimo quechua de Huarochirí ([1608?] Taylor1987), comúnmente conocido bajo el título agregado a la traducción de Arguedas y Duviols (1966) Dioses y Hombres de Huarochirí.

El vínculo con los hombres de la narrativa quechua fue el kuraka huarochirano Don Gerónimo Cancho Guaman, futuro protagonista de una parte del manuscrito, quien vino a testimoniar a favor de Picoy. Cancho Guaman, padre del precoz extirpador de "ídolos" Cristóbal Choque Casa, figura en la narrativa quechua como prototipo del kuraka "idólatra" o "encubridor de ídolos". En el litigio lo vemos como un señor étnico de rango intermedio, leal defensor de los intereses de los "hijos de Tutay Quiri" en la waranka de Checa durante la transición al "colonialismo maduro".

Guaman Poma, en cambio, aparentemente conoció los hechos del pleito ex post facto. Como en muchos contextos, enaltece a los kurakas que pactaron con el Rey Emperador Carlos V, en este caso Condorchagua y Pomachagua de Yaucha. Además simpatizó con Yaucha por definir su kurakazgo como emparentado con la nobleza "yarovilca allauca huánuco", cuya legitimidad fue obsesión del "autor y príncipe". El punto más interesante, en cuanto a Guaman Poma, es un aparente vínculo entre el pleito y dos de sus imágenes famosas de los khipukamayuq o maestros de khipu imperiales. Se trata de homónimos de los personajes cruciales del linaje Yaucha, Condorchagua y Pomachagua. Uno de éstos es descrito como contador mayor del imperio (Guaman Poma 1980[1613]:332) y el otro como custodio del depósito imperial, títulos clarificados a través de la lectura del pleito. El triángulo tiene, además, relevancia técnica acerca del rol de la contabilidad por khipu en la transición al dominio español. El hecho de que los autores de estas dos fuentes hayan prestado atención a personas involucradas en el pleito Guamanyanac-Caxayauri deja abierta la posibilidad de una interacción que conecte las dos fuentes.

\section{Antecedentes del Pleito Guamanyanac/Caxayauri en Mama: Genealogía, Khipus y Piedras}

La sociedad indígena del Rímac medio y alto comienza a dejar huella documental desde los repartimientos pizarrinos; su primer encomendero fue Juan Fernández. En 1548 (AGI/S Lima 121) el presidente La Gasca dio título para transferir la encomienda del repartimiento de Huarochirí, en ese momento encomendada en la viuda de Fernández, a Gerónimo de Sylba. Por parte de los naturales este traspaso quedó ratificado por un tal "Pomachagua caçique prençipal del balle e tierras de Guanchu" (lo que posteriormente sería S. Mateo de Huánchor).

Pomachagua merece más estudio por dos razones. Primero, porque la pretensión de sus descendientes a ser "caciques principales", no sólo de Huánchor sino además de Mama, fue el punto crucial en el debate. Como veremos, el poderío sobre Mama parece en realidad haberse basado en maniobras políticas de Pomachagua durante la crisis del incario, a partir de 1532 y el encuentro de Cajamarca, y estas estratagemas revelan algo del trasfondo político-cultural de los textos clásicos. Segundo, Pomachagua es interesante porque fue khipukamayuq del incario. Su conducta resulta sugerente para entender el rol de los contadores en el proceso político. Su lugar en la iconografía de los khipus no podría ser más central. En el dibujo que Guaman Poma hizo del "depoçito del inga" (1980 [1613]:309) el khipukamayuq que muestra el inventario anudado de la qullka a su soberano "topa ynga yupanqui" se llama "Administrador Suyuyoc Apo Pomachagua" (Figura 1).

De manera similar Condorchagua, hermano de Pomachagua, aparenta ser otro khipukamayuq, cuya imagen queda grabada en la imaginación de cuantos estudian la antigua "tecnología del intelecto" (frase de Jack Goody), el "CONTADOR MAIOR I TEZORERO TAVANTINSUIO QUIPOC CVRACA CONDOR CHAVA", dibujado por Guaman Poma (1980 [1813]:332; Figura 2). Gracias al pleito sabemos que Condorchagua, hermano de Pomachagua, fue asimismo "en el tienpo del ynga ...contador y quipocamayo del ynga" (f.153v).

El hábil funcionario toledano Diego Dávila Brizeño ([1583] 1965) hizo un informe fechado el 24 de julio de 1585 con el propósito de averiguar y ejecutar el testamento del difunto kuraka de Yaucha 


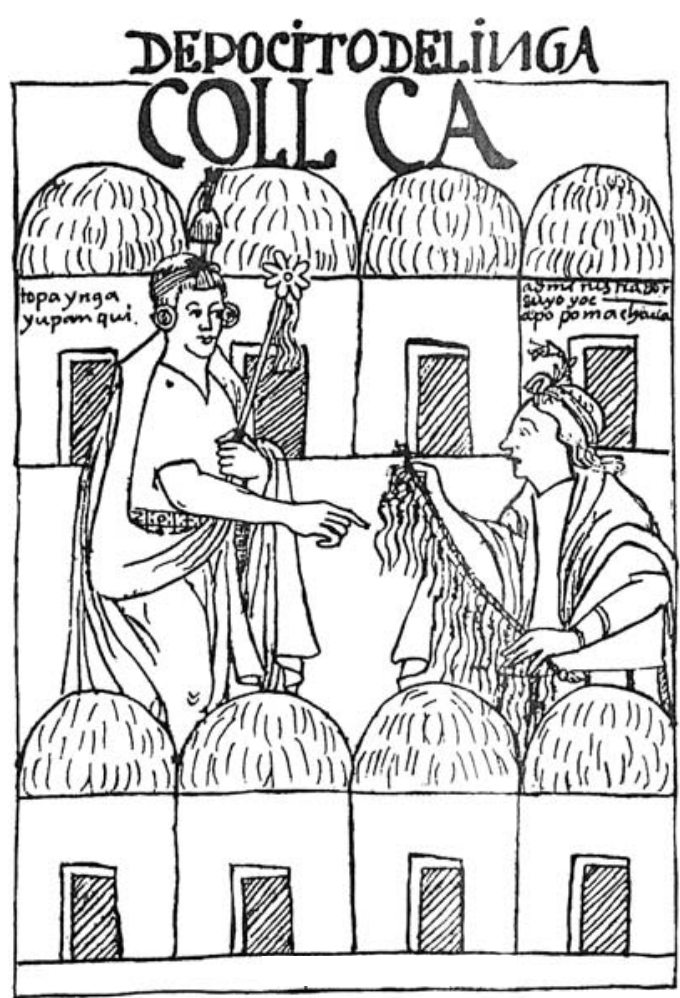

Figura 1. "Apo poma chaua" (a la derecha) presenta cuentas en khipu a "topa ynga yupanqui”" (Guaman Poma 1980 [1613]:309). "Apo poma chaua" (right) presents accounts by khipu to "topa ynga yupanqui" (Guaman Poma 1980 [1613]:309).

en Huánchor D. Diego Quispitapra (f.83r). Su informe se reproduce en Espinoza Soriano (1983-8: 243-245). Este documento reviste interés, pues intenta sugerir la función del khipukamayuq en cuestiones de genealogía. Además identifica, independientemente del proceso de 1588-90, a los hermanos Pomachagua y Condorchagua, agregando los nombres de bautizo que adquirieron en el lapso entre 1548-1583, a saber, Gerónimo para el primero y Pedro para el segundo. El texto fue incluido en el proceso por ser relevante a la sucesión de Yaucha. Espinoza Soriano ha publicado la transcripción entre los extractos documentales adjuntos a su artículo (1983-84:243-245). Las citas a continuación se toman de la transcripción hecha por el presente autor y por Lorena Toledo; discrepan en algunos detalles de la versión publicada. Examinemos dos puntos: primero, el modo de empleo del khipu en contexto de la genealogía, y segundo, las identidades de Condorchagua y Pomachagua.

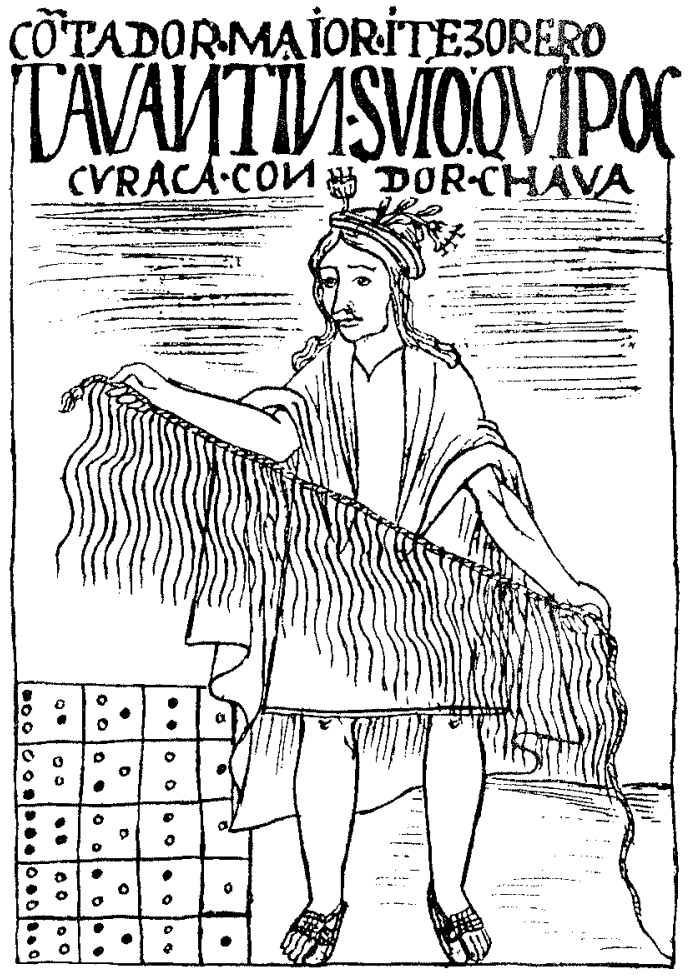

Figura 2. "Curaca Condor Chaua" contador mayor del Inka (Guaman Poma 1980 [1613]:332).

“Curaca Condor Chaua” chief accountant to the Inka (Guaman Poma 1980 [1613]:332).

Al cotejarse la Nueva Corónica con el proceso y con el informe de Dávila Brizeño surge una duda cronológica: ¿Es posible que dos hombres ya maduros y dueños de importantes títulos inka bajo Tupaq Inka Yupanki, penúltimo soberano anterior a la invasión española, puedan identificarse con sus homónimos quienes, como veremos, actuaron con brío durante la crisis de la invasión española y hasta 1548 ? Rowe (1945:277) calcula 14711493, como una cronología plausible del reinado de Tupaq Inka Yupanki. A primera vista la asociación con un Inka antiguo parece indicar que los khipukamayuq dibujados habrían sido hombres de otra generación, con nombres similares. De hecho, debemos tomar en cuenta la posibilidad de que ciertos nombres rituales se hayan conferido a múltiples individuos. Sin embargo, es probable que los homónimos en el pleito y en Guaman Poma hayan sido los mismos individuos. Suponiendo que fueran jóvenes al final del reinado de Tupaq Inka Yupanki, pudieron haber vivido hasta la década de 1540. Pero 
en todo caso, el hecho de Tupaq Inka Yupanki que haya muerto varias décadas antes no importa mucho, porque sus bienes se legaron a la posteridad como propiedad de la momia real con su panaka o corporación conmemorativa. Habría sido raro si tal corporación no hubiera tenido un "quipocamayo y mayordomo de todas las açiendas del ynga topa" (f.146r) aún mucho después de su deceso.

Veamos la metodología empleada al consultar los khipus yauchas: A fin de esclarecer la herencia, Dávila Brizeño -buen conocedor de la cultura regional- entrevistó en grupo a las autoridades de las tres reducciones importantes del Rímac alto, a saber San Mateo de Huánchor, San Juan de Matucana y San Jerónimo de Surco, en presencia de numerosos observadores indígenas y de un traductor. Pidió que las autoridades conjuntamente prepararan y presentaran, en paño, un dibujo que representase la genealogía y el mando ("y para que no hierren se junten ellos alla / aparte / y en un papel u paño le traigan pintado los caçiques que an sido desdel tienpo de guayna capac y entrada de los españoles hasta agora que murio su caçique Diego Quispitapra", f.83r).

Tras deliberar dos días, las autoridades indígenas presentaron el resultado. Hablaron en lo que parece haber sido sesión abierta, a juzgar por la presencia de "prinçipales y otros muchos yndios de los dichos pueblos de san mateo de guanchor y san juan de matocana / y san geronimio de surco y alcaldes rregidores dellos y rrezervados de tasa y segunda persona". Lo interesante es que los kurakas decidieron no seguir la sugerencia de Dávila Brizeño, que pintasen un árbol genealógico (se supone, más o menos al estilo español). Más bien, optaron por una exposición a base de khipus y piedras. En el siguiente extracto subrayado es original al texto y el resaltado en negrita es al texto agregado:

rrespondieron todos de conformydad que ellos avian hablado munchas vezes en lo que se les mando y que alli estauan todos los yndios antiguos viejos que se acuerdan y vieron los dichos caçiques que los mandavan desde el tiempo de guaina capac hasta oi y asi luego pusieron por piedras en el suelo a un caçique que se llamo caruayabri que este fue caçique desta guaranga de yaucha que asi se llama los yndios rreduzidos a este dicho pueblo de san mateo de guanchur y este carva yauri tuvo dos hijos en una muger y murio antes que entrasen los españoles en este rreino y se llamo charabi y fueron de yanamarca entrambos marido y muger de un pueblo desta guaranga de yaucha [f.83v/] El hijo mayor deste dicho viejo caruayauri se llamo don geronimo poma chagua desde que fue [cristi]ano y el sigundo se llamo don pedro condordor [sic] chagua. este don pedro condor chagua governo desde que entraron los españoles hasta el tiempo del de la gasca y el conde de nyeba y con el habla la tasa [sic] y este tuvo sinco hijos el mayor se llamo atayauri y el segundo se llamo don juan guaman chava que çuçedio en el caçicazgo a su padre y el terçero se llamo don pedro nuna chaua y el quarto don juan de godoi que oi bive y el quinto se llama don martin carua chagua que oi bive y el dicho don juan guaman chava dexo un hijo natural que oi govierna por muerte de don diego quispi tapra que agora murio y por saberlo hazer y sirvio ya / ocho meses antes que muriese el dicho don diego caçique su primo sigundo y agora / se nombro por el señor corregidor / por tal governador hasta que su excelencia nombre al que fuere servido y por tal lo nombro a pedimyento de todos los caçiques desta dicha guaranga de yaucha en junta general / deste dicho rrepartimyento que para ello se fizo - / el hijo mayor del dicho viejo carua yauri que se llamo don geronimo poma chagua tuvo tres hijos el mayor se llamo diego quispi chagua y el sigundo don diego tapra yauri y el terçero don mateo tapraqyauri [sic] e fue cacique muncho tiempo el don juan su primo y no dexo fijos y çuçediole en el cacicasgo su sobrino / don diego quispi taprac hijo del hermano mayor del dicho don mateo que se llamo don diego quispi chagua como esta dicho que fue caçique el dicho su hijo don diego quispi taprac que murio a onze deste presente mes de julio susodicho no dexo hijos sino un hermano bastardo que se llama / diego cullqui chagua y este dicho cullqui chaua tiene un fijo de quatro $u$ sinco años que se llama don mateo y a este don mateo no nombra el dicho difunto don 
diego quispitaprac por su eredero y declara en el dicho testamento que fizo a su muerte que aquel dicho don mateo su sobrino le viene el caçicasgo de derecho y el otro hermano del dicho don mateo paucaryauri / que se llama don diego taprac yauri tiene dos hijos. el mayor que se llama don geronimo caxa yauri de hasta quinze años y otro pequeno [sic] de nueve o diez años y estos dichos yndios son los decendientes / son los decendientes [sic] del dicho viejo caruayauri/ que se llamo don diego tapraqyauri [sic]. y de los dos hermanos hijos deste dicho viejo y cada parçialidad destas dos a avido caçiques que an governado hasta agora como dicho es y esta descriçion dieron don diego paruva segunda persona / deste dicho rrepartimyento de mama y de edad de sesenta años y guauquilcasca de sesenta años y guaucar guahaman su $[\mathbf{f . 8 4} \mathrm{r} /]$ contador / o quipocamaio de secenta años y alonso guamanyacollca contador maior deste dicho rrepartimyento de mama de edad de sinquenta años. estando presentes don juan de godoi pomavillca y don martyn carua chava nyetos del viejo carua yauri $\mathbf{y}$ don geronimo caxaiauri y don geronimo xaxapoma governador al presente y hecha esta dicha declaraçion y averiguaçion con juramento en forma de derecho y lenguas asimysmo con juramento que les tomo el señor corregidor a todos los sobre dichos que dirian verdad y todos se afirmaron en lo que tienen declarado. sin discrepar nynguno / en veinte y seis dias de junyo de myll e quinientos y ochenta y sinco años y despues se rratificaron todos los sobre dichos ante el señor corregidor diego dauila brizeño y de nosotros los escrivanos y lenguas en la española y la general de los yndios con juramento que se nos tomo por el dicho señor corregidor de hazer bien y fielmente sus oficios de escrivanos y lenguas a my don pablo guari tapral prinçipal y a my juan clemente escrivano de cabildo deste dicho pueblo de san mateo de guachur [sic] y por verdad lo firmamos de nuestros nombres y firmo el señor corregidor a treinta y un dias del mes de julio de myll e quinientos y ochenta $\mathrm{y}$ sinco años diego davila brizeño / don pabo [sic] escrivano nombrado y lengua - juan clemente villca escrivano de cabildo y lengua.

Este testimonio puede ser relevante a un tema vigente en el debate sobre el khipu, a saber, el uso de las piedras como fichas para interpretar los khipus. Las frases resaltadas explican que los autores de la genealogía fueron cuatro: dos nobles de la vieja generación, ambos nacidos unos diez años antes de la conquista pizarrina, y dos "contadores" suyos. El contador coetáneo de los nobles ostenta título de "quipocamaio". Él habría aprendido el arte en ca. 1540, cuando aún vivían muchos maestros capacitados bajo el Tawantinsuyu. Se puede suponer que los khipus afianzaron la genealogía aducida; sin embargo, no se hace explícita la consulta a los khipus como el acto de testimonio, sino la presentación de la genealogía en forma de diagrama hecha con piedras, como explicación oral.

El procedimiento hace pensar en un caso detallado por Platt (2002:247-250), sobre el empleo de piedras para manifestar el contenido de ciertos cordeles con cuentas de 1548-1551. Un khipukamayuq interpretaba los cordeles, mientras otro transcribía lo leído con "piedrecillas" en el suelo. El escrutinio de las piedritas mediatizó en la formulación del testimonio final. La naturaleza de esta mediación constituye un eje importante dentro del debate actual sobre el "código de los khipus" (Ascher y Ascher 1997). Según el modelo propuesto por Urton (2002:31), las piedras, blancas y negras, funcionaron para traducir un conjunto de siete variables binarias, correspondientes a propiedades físicas de cada colgante (p. ej. su torsión en S o en Z, su unión con el cordel tronco mediante lazo en "recto" o en "dorso", etc.). Las variables binarias, según Urton, formaron un despliegue digital compacto, comparable al despliegue digital de los ocho bits del código ASCII para computación. Estos valores binarios, según enfatiza Urton, podían asignarse a múltiples significados finales, de acuerdo a los múltiples contextos.

¿Cuál fue el rol del "quipocamaio guaucar guahaman" y su contraparte "alonso guamanyacollca contador maior" en la formulación del testimonio conjunto de "don diego paruva ...y guauquilcasca"? Los "contadores", al estudiar los cordeles o posiblemente al escuchar alguna verbalización de ellos, habrían cruzado sus cono- 
cimientos para manipular las piedras, hasta llegar a una representación coherente y consensual de los hechos.

Los testimonios hasta ahora conocidos referentes al método cordel-más-piedra tratan de la contabilidad propiamente tal, con datos principalmente numéricos. Lo novedoso aquí es que en Huánchor se trató de hechos no numéricos. Si en efecto, Dávila Brizeño presenció la confección de una narrativa histórica (la citada genealogía) a base de datos anudados convertidos en diagrama genealógico, estuvo presente ante una técnica tantas veces citada, pero no bien esclarecida de la capacidad de los khipus para narrar historias (tema desarrollado en el más actualizado y reciente compendio de estudios sobre khipus: Quilter y Urton 2002). La genealogía vertida en prosa por Dávila Brizeño contiene números cardinales (números de años y meses) y números ordinales (orden de generaciones, orden de nacimiento desde el primogénito), pero además es preciso en nombres personales y sucesos. La precisión de números de años y meses transcurridos nos obliga a pensar que hayan sido actualizados periódicamente (Radicati 1965), o bien que hayan contenido fechas absolutas, lo cual implicaría un sistema de datación hasta ahora ignorado en el contexto inka.

En el mismo retrato de Condor Chaua por Guaman Poma (Figura 1) las piedras fichas aparecen en tabla cuadriculada, comúnmente llamada yupana (contar, contable), visible a la izquierda inferior. ¿Puede ser que en el dibujo Guaman Poma o haga alusión al viejo maestro de cordeles Condor Chaua como transmisor del método ca. 1585 y otra vez ca. 1588 defendiendo a los intereses de su descendencia?

Volviendo a considerar el contenido del testimonio, los dos ancianos y sus respectivos khipukamayuq aseveran que la sucesión de la waranka de Yaucha se podía describir en términos de dos patrilinajes fraternos, cuyo ancestro común fue Caruayauri. Durante seis transmisiones de mando, y a diferencia del esquema español que contempla la primogenitura, la sucesión demostró la transmisión fraterna (Rostworowski 1960) y hasta la sucesión de primos patrilaterales. Los dos hermanos fundadores de linajes fraternos, hijos de Caruayauri y su esposa Charabi, fueron Pomachagua y Condorchagua. Nacieron bajo el inkanato y vivieron la conquista. En las páginas que siguen vamos a observar primero que ambos hermanos tu- vieron el mando de Yaucha en determinados momentos, pero con Pomachagua en la posición principal y Condorchagua como su reemplazo; y segundo, que ambos fueron khipukamayuq por derecho propio.

\section{Pomachagua de Yaucha (Huánchor) Durante la Invasión Pizarrina y un Takiy o Canto de Guaman Poma}

Según la parte Yaucha, antes de los inka, había kurakas de guaranga en Picoy, Yaucha, y Cayao. Ninguno fue elevado sobre el otro, sino que cada kuraka individual y libremente se subordinaba a los señores de Huarochirí. En tiempos inka, "Topa Ynga Yupanqui" y otros soberanos ratificaban a cada señor dando el duo (trono), chacras, cumbi, joyas, etc. Así que, al no tener señor hegemónico sobre sí, cada cual podía enviar embajada a los españoles y dar vasallaje voluntariamente. El supuesto derecho a gobernar Picoy fue otorgado a Pomachagua por Pizarro a cambio de dicho vasa1laje.

Según sus descendientes y paisanos Pomachagua fue el cuarto kuraka de la genealogía dinástica yaucha. En su persona se unificaron poderes de la etnia con un cargo alto del Tawantinsuyu, el de "quipocamayo y mayordomo de todas las açiendas del ynga topa" (f.146r), o sea, de la momia y panaka del penúltimo inka prehispánico. Por tal, "hera camachico ['dirigente, mandón'] de los yndios que guardaban los ganados del ynga y ansimismo tenía cuidado de guardar los cunbis y maizes y papas y demas cossas del dicho ynga" (f.121v). La descripción coincide con los bienes almacenados que acompaña al dibujo del "depocito" de Tupaq Inka Yupanki (Guaman Poma 1980 [1613]:310). Ya que las panaka gozaban de cierta soberanía residual sobre los bienes de la momia, Pomachagua no habría sido funcionario directo del monarca actual (sucesivamente Wayna Qhapaq, Waskhar y Atawallpa) sino custodio de bienes reales asignados aparte. Este hecho le habría facilitado un importante margen de maniobra, el cual habría aumentado a medida que la guerra entre los sucesores de Wayna Qhapaq, y luego la lucha con España, complicaron el cuadro político inka. ¿Habrá sido un caso paralelo al del Cuzco, donde varios panaka pudieron actuar con cierta autonomía durante la primera fase de la época colonial? 
Pomachagua fue considerado por sus paisanos como "belicoso y de buen entendimiento" (f.66v). Militó con las huestes inka en la guerra de Quito liderando un contingente grande de ejército con base en Jauja. Dejó por kuraka interino en Yaucha a su hermano Condorchagua (f.62v).

Al regreso de las guerras norteñas Pomachagua reposaba en su casa en Yanamarca (de Yaucha) cuando se tuvo la noticia de la llegada de los españoles al cercano santuario de Pachacamac. Con otros naturales, salió a saludar a los españoles y allí oyó la noticia de que Pizarro estaba en "Caxamarca la grande" (f.66r). Dejó el kurakazgo yaucha nuevamente en manos de su hermano Condorchagua y se fue a Cajamarca. Llegó a Cajamarca cargado de regalos de oro, plata, cumbi y gente de servicio. Allí pactó alianza con el marqués. Pizarro reciprocó con contradones de "bestido de damasco carmesi" (f.103r), espada y daga. Estas prendas españolas evidentemente impresionaron profundamente a sus contemporáneos incluso muchos pertenecientes al kurakazgo de Picoy: "y que como le bian los yndios con aquellas armas y que las traya con liçencia del dicho marques le enpeçaron a temer y a serbir y no porque fuese caçique de el dicho rrepartimyento ni lo obiesen sido sus passados" (f.110v).

Desde aquel viaje "bino con brio y enpeço a enseñorearse de este dicho caçicazgo" de Picoy (f.156r). Logró convencer a los yunka que el marqués "le auia echo merçed de nonbrarle por caçique de las tres guarangas ynclusas en el dicho rrepartimiento de mama" (f.146r). Con este golpe de teatro Pomachagua ganó la iniciativa e inició la dominación sobre Mama que, medio siglo después y al cabo de varios cambios de mando, iba a dar pie al pleito de 1588 .

Nos permitimos la especulación de que el mencionado encuentro con los españoles en Pachacamac y Cajamarca, la fracasada respuesta estratégica de los soberanos inka y la formación de un pacto pizarrino que resultó ventajoso para los kurakas huarochiranos, puede constituir el trasfondo histórico que inspiró el capítulo 14 del manuscrito anónimo quechua de Huarochirí -una versión recopilada unos setenta años después, cuando los hechos se contaban en un marco ya bastante mitologizado. En el dicho capítulo, el demiurgo y trickster Viracocha induce al inka a mandar un mensajero a Pachacamac para recibir un regalo maravilloso. Por mensajeros el Inka envía chamanes capaces de transformarse en aves veloces, que vuelan a la costa. El mensajero-chamán que recoge el regalo no aguanta la tentación de abrir la caja que lo contiene. Ve que el regalo es una mujer muy bella con cabello como oro. La rubia enviada desde Pachacamac puede representar simbólicamente la oferta de vasallaje al rey de los españoles rubios; era normal que la aceptación de esposasregalos de mano del Inka se entendía como señal de endeudamiento político. La oferta de la dama, pues, habrá significado la potencial subordinación a España. La apertura prematura de la caja por parte del mensajero puede referirse al oportunismo de los kurakas -por ejemplo, Pomachagua- que se aprovecharon de la coyuntura para ofrecer independientemente su vasallaje a España.

En el capítulo 14, el Inka perdona al mensajero traicionero, divide su dominio en dos y se retira con su mujer mágica mientras los demás líderes comienzan a rivalizar por la supremacía, cada cual diciendo "ñocarac ñocarac" ('yo primero' '- no, yo'). El mito parece sugerir que al generalizarse el contacto con españoles la supremacía del Inka se derrumba. Este deja de funcionar como vocero de todos y la guerra entre Pizarro y el Inka se complica por múltiples luchas dinásticas locales. Tal fue el desenlace en el valle del Rímac.

Guaman Poma menciona otra vez a un "Poma Chava" en el contexto de su capítulo sobre festejos de los pueblos de los cuatro suyu. Al hablar de las "fiestas de los Chinchaisuio" (Guaman Poma 1980 [1613], dibujo 295), transcribe un enigmático canto festivo, puntuado y dividido en versos por los editores de la siguiente manera:

Ayauaya ayaua

Haucay patapi, Cuci Patapi

Capac Yncauan

Camaycuscayqui, maymi?

Capac Apo Uaman Chava

Poma Chava Yaro y Uilca

camcho canqui Uira Cocha?

Apa cochata Caxamarcapi

Capac Apo rrey emperadorta

Muchaycoclla

Payuan uillanacoclla

Uaman Poma Ayalalla

Apo Chauap uilcallan

Uayac Pomap mitallan 
La edición de Murra, Adorno y Urioste (Guaman Poma 1980 [1613]) surte la siguiente traducción:

\section{[Ayawaya ayawa}

En la Hawkay Pata, en Kusi Pata

Junto al Inka poderoso,

¿Dónde está tu capitán?

¿Eres tú el señor rey Waman Chawa,

Puma Chawa, el Yaru y Willka,

eres tú el Wira Qucha?

¡Por la laguna de Apa, en Cajamarca

Al señor poderoso, al rey emperador

Ofreciendo su lealtad,

Consultando con él,

Está Waman Puma de Ayala

El noble de Apu Chawa,

El compañero de Wayaq Puma!]

Este texto como casi todos los taki (cantos quechuas) de Guaman Poma presenta escabrosas dificultades, por las cuales el texto admite traducciones alternativas en múltiples puntos. Estamos de acuerdo con los editores al entender la letra como compuesta de dos preguntas seguidas por una respuesta o, según se analice la sintaxis, dos respuestas. La duda en cuanto a la sintaxis nace de la total ausencia de verbos principales (y no participiales) que no sean formas de kay 'ser, estar'. Kay en tercera persona presente ( $k a n$ ) puede ser suprimido, formando así la "cópula cero" común en quechua. El cantor se vale de la cópula cero en los últimos siete versos, pero no se sabe cuántas veces, de manera que no queda evidente si contienen una oración o más de una. Dentro de la norma poética quechua colonial, donde prima el paralelismo, se podrían esperar dos. Bajo tal suposición podríamos hipotetizar un kan implícito después de muchaycoclla y otro después de mitallan. Otras ambigüedades, esta vez de carácter léxico, existen en torno a Uira Cocha, que en Guaman Poma como en el quechua cuzqueño moderno bien puede significar 'español' tanto como el nombre de la deidad invisible, Apa Cocha, sin traducción clara y los sustantivos polisémicos mita y uilca.

A grandes rasgos, una posible lectura del canto sería que comienza con una pregunta retórica dirigida a una segunda persona no identificada: en las dos plazas ceremoniales del Cuzco, ¿dónde está tu capitán, el soberano Inka? Puede ser que la segunda persona 'tú' a la cual se dirige el canto sea identificada en la segunda pregunta como los dos hombres Guaman Chaua y -el que nos interesaPoma Chaua "Yaro y Uillca" (o sea, de la nobleza que Guaman Poma designa como su propio linaje; Amat Olazábal 1992). "Uaman Chava" posiblemente equivale al incap rantin o 'segunda persona' del mismo nombre dibujada en otro contexto (1980 [1613]:313). Mientras tanto, en Cajamarca el linaje Guaman Poma ya está solemnizando el pacto con el rey cristiano. A estos dos se formula la pregunta: ¿Camcho canqui Uira Cocha? ¿Eres tú el español?

Los siete versos que siguen y que dan respuesta se inician con un locativo que hace contraste con las plazas ceremoniales del Cuzco, nombrando el lejano Cajamarca como el local donde está "tu capitán". En Cajamarca, está -con sorpresa lo oímosGuaman Poma de Ayala; los últimos dos versos son epítetos o títulos ceremoniales agregados a su nombre. Admiten traducción como 'el nieto de Apu Chawa' y 'el descendiente de Wayaq Puma'. En Cajamarca, el mismo autor (¡según se imagina imaginado por los Chinchaysuyos!) está ofreciendo devoción a Apa Cocha, "epíteto de Viracocha en una de las oraciones quechuas registradas por Cristóbal de Molina en 1575" (según uno de los evaluadores anónimos de este trabajo) y en un verso paralelo, simultáneamente ofreciendo su lealtad al rrey emperador. El rey emperador -o sea, el rey y emperador Carlos V- es nombrado en español. Estos dos versos en paralelo forman una variante de la tantas veces expresada autoimagen de Guaman Poma como encarnación de un pacto primordial entre el Perú y España, en otro contexto efectuado por el padre del "autor y príncipe". Igualmente expresa su autoimagen como devoto intuitivo del verdadero Dios invisible (Guaman Poma 1980[1613]:348-349, 1991[1595]:159).

En fin: el taki implica que Poma Chaua "Yaro Uillca" al encontrar la soberanía cuzqueña vacía, debe su lealtad a la alianza hispano-andina, justificada por la equivalencia entre Dios y Wira Qucha, que ya se formaba en Cajamarca, liderada por el linaje de Guaman Poma. Una traducción en este sentido sería:

Ayauaya ayaua

En Haucay Pata, en Cuci Pata,

Junto al Inca poderoso, ¿Dónde está tu capitán? 
Gran señor Uaman Chava

Poma Chava Yaro Uilca,

¿Eres tú el Uira Cocha?

Solo Guaman Poma de Ayala

Está adorando, y está conversando

[Adorando] a Apa Cocha en Cajamarca,

[Conversando] con el poderoso señor

Rey Emperador.

Él, el nieto de Apo Chaua,

Él, descendiente de Uayac Poma.

En el intervalo caótico, entre 1532-1535, Pomachagua resultó ser excelente ejemplo de los líderes que se valieron del oportunismo español y del inestable equilibrio de las fuerzas locales para establecer hegemonías regionales. En 1535, el último intento cuzqueño de desalojar a los invasores puso a prueba la estrategia "hispano-andino" (Stern 1982:7-50). Pomachagua pudo convertir su alianza política en cacicazgo principal dentro del valle del Rímac, según sus testigos, apoyando la resistencia española contra el sitio de la nueva capital española por elementos proinka. Según el pleito, muchos plebeyos "rebeldes" y pertencientes a los tres "miles" de Mama se juntaron con los inkas para cercar a Los Reyes en 1535:

y despues los dichos yndios de picoy cayao y yaucha oyeron dezir como venya el ynga del cuzco a dar batalla contra el marques e demas españoles y llego a la zibdad de los rreyes sabido desto los dichos yndios de cayao e yaucha e picoy se rrevelaron y ffueron a la zibdad de los reyes a faboreçer al dicho ynga e que solamente se fueron a poner debaxo de los españoles el dicho don geronimo poma chagua y ticsy guaman padre del dicho don antonio guaman yanac que trata este testigo y otros kurakas e despues que mataron al dicho ynga en la zibdad de los reyes sabido por el dicho cacique que se avian rrevelado los dichos yndios de picoy y cayao y yaucha e que los dichos don geronimo poma chagua y demas [tarjado: des] kurakas que asi fueron con el sabido por el dicho marques que avian ido en su ayuda y contra los yndios rreveldes el dicho marques le avia fecho curaca de todo el dicho rrepartimyento de mama picoy y yaucha y cayao al dicho don geronimo poma chagua y le dio [tierras?] y armas espada y lança y assi este testigo le vido ser tal cazique prinçipal de todo el dicho rrepartimyento de mama al dicho don geronimo poma chagua y todos los prinçipales e yndios del dicho rrepartimyento le rrespetaron como a tal cazique (Testigo Don Diego Pariona, de 70 años; 8 febrero 1589 , f.70r-71v).

\section{El Rímac Medio a Ojos de los Autores del Manuscrito Anónimo Quechua de Huarochirí (1608?)}

Las perspectivas de los narradores del libro quechua de 1608 (?) emanan desde las serranías de Huarochirí central. Los varios narradores toman por puntos referenciales a Llacsa Tampu, "pueblo viejo", hoy escasamente habitado, vecino a San Damián, o el cercano San Cristóbal de Concha, o la reducción de Santa María Jesús de Huarochirí, o San Lorenzo de Quinti. Sin embargo, en el prólogo el redactor promete dar cuenta de "todos los pueblos" pertenecientes a los "hijos de Paria Caca" y no sólo de las alturas. Hacia 1600 el "archipiélago vertical" estaba en las últimas etapas del retroceso. En los valles bajos de Huarochirí los narradores ya habían perdido el control de sus antiguos enclaves con cocales. Sin embargo, los narradores a veces intentan cumplir con el compromiso de explicar la historia legendaria de "todos los pueblos" donde moraban sus ancestros.

El capítulo 13 discute en detalle el culto a los dioses del pueblo subtropical de Mama, reducción también involucrada en el pleito de 1588. ¿Por qué les interesó Mama precisamente? Por un lado, los ayllus reducidos en San Damián, notablemente los Checa (quienes llevan la voz cantante del libro) poseían una 'isla' o enclave de cocales en tierra yunga, en Suquia Cancha, a orillas del Rímac, que formaba un hermoso oasis en medio de los cerros áridos. La "isla" Checa de Suquia Cancha existió en asociación "multiétnica" según la definió Murra (1975) con el dominio político de los yunka de Mama, estando ubicada en San Gerónimo de Surco la reducción donde habitaba el ayllu Picoy. ¿Habrá sido por esto que los testigos provenientes de los pueblos checas dieron sus testimonios en el litigio a favor de Guamanyanac de Picoy? 
Por otro lado, Mama poseía importancia especial en el sistema religioso de los Checa, por ser sede de la gran diosa yunca Chaupi Namca. Un templo en Mama hospedaba el principal de cinco cultos de wak'as consideradas en conjunto como manifestaciones "hijos" o "hermanas" de Chaupi Namca. Los otros cuatro se distribuían por varios pueblos de yunkas con enclaves checas, especialmente Sisicaya y Chillaco en el valle del Lurín. Chaupi Namca en su totalidad quinquepartita se concebía como la contraparte hembra del wak'a 'padre' de los huarochiranos, el nevado deificado Paria Caca. Los checa tomaban parte entusiasta en los cultos de las "hijas" o "hermanas" de Chaupi Namca. A la fecha del inicio del pleito, en 1588, el templo de Chaupi Namca ya habría sido destrozado por Diego Dávila Brizeño durante la reducción de San Pedro Mama. Pero los capítulos 10 y 13 del manuscrito anónimo quechua (Taylor 1987:192203, 222-241) informan que su culto subsistió tenazmente en los enclaves checas del Lurín. El refugio otorgado a Chaupi Namca, tanto como la convivencia en los cocales, pudo ser un motivo de la alianza Checa-Picoy.

\section{Aprendizaje y Testimonio de Don Geronimo Cancho Guaman, un Kuraka en el Manuscrito Anónimo Quechua}

La larga contienda Yaucha-Picoy fue muy comentada en la reducción de San Damián de Uructambo o de Checa, donde se compuso el manuscrito anónimo quechua (f.106v). El pleito contiene testimonios dados por siete hombres oriundos de lugares cuyos habitantes o dueños participaron en la confección de la fuente quechua (Gonçalo Caxatacma de san Damián f.73r, Martyn Chumbi Sirve [sic?] de san Damián f.73v, Martín Anchelivia de Chauti f.57r, Cristoval Carvalivia de Chaute f.60v, y Diego Julca Poma de Suquiacancha f.59r). Más importantes que éstos cinco, fueron los testigos Don Domingo Samari (BN/L ms. B-1483) y Don Gerónimo Cancho Guaman, ambos caciques de la reducción de San Damián, donde residió el Padre Francisco de Ávila, y donde el manuscrito tuvo su origen (Acosta Rodríguez 1987). El testimonio de Samari y Cancho Guaman fue dado en conjunto y ocupa las fojas $105 \mathrm{v}-112 \mathrm{r}$. Se reproduce en Espinoza Soriano (1983-84:266-268).

Don Geronimo Cancho Guaman, kuraka de San Damián, es una figura muy importante en el manuscrito anónimo quechua de Huarochirí. El capítulo 20 inicia el largo relato sobre su hijo Don Cristóbal Choque Casa y su lucha contra los wak'a o divinidades prehispanas. Se hace hincapié en el contraste entre el viejo kuraka Don Gerónimo, cristiano pero profundamente dominado por la mentalidad "idólatra", y su hijo, férreo enemigo de los "demonios malos antiguos". En el relato influido, o posiblemente dado, por el joven Don Cristóbal, su padre Don Gerónimo Cancho Guaman queda cruelmente satirizado por su indecisión frente al cristianismo y las "idolatrías".

Los capítulos 20 y 21 narran la historia del padre y del hijo con una intimidad psicológica sorprendente. Comienza con el descubrimiento del wak'a Llocllay Huancupa por una joven del "mil" de los checa. Al revelarse mediante un oráculo como "hijo" (avatar, divinidad delegada) de Pacha Kamaq, el nuevo y temible wak' $a$ Llocllay Huancupa, cuya forma exterior aparentemente fue de un oso, comenzó a funcionar como protector de los Checa. Pero cuando vino un tal Padre Cristóbal de Castilla, su culto fue suprimido. Ya que "[el Padre Castilla y] el curaca... Don Gerónimo Canchoguaman... aborrecían estas cosas, [la gente] ya no celebraba este culto" (Taylor 1987:300-301).

Cancho Guaman, sin embargo, no resultó constante en su rechazo del wak'a. Bajo el flagelo de la "gran epidemia de sarampión" don Gerónimo Cancho Guaman cedió a una creencia popular: que Llocllay Huancupa había enviado la enfermedad para castigar a quienes habían abandonado su culto. La gente volvió a adorarlo en su santuario clandestino (purum huasi). Y el mismo Gerónimo "en el momento de morir, engañado por el demonio, cayó en este pecado (la idolatría). Engañado por varios hombres ancianos y diabólicos, cuando a punto de morir, se confesó [segun los ritos gentílicos]". El narrador, posiblemente identificado como su hijo Don Cristóbal, comentó: "Nuestro señor Dios sabrá dónde se encuentra [ahora]" (Taylor 1987:20:302-303). El inolvidable capítulo 21 prosigue contando el conflicto visionario entre Cristóbal y Llocllay Huancupa.

El litigio entre Yaucha y Picoy aclara apreciablemente nuestros conocimientos de quién fue Gerónimo Cancho Guaman y cómo se formó. Por lo tanto aclara, en parte, el trasfondo político del manuscrito quechua. Al comenzar su testimonio, Cancho Guaman afirmó tener 60 años, lo cual implica que nació ca. 1530; no llegó a escribir ni a 
hablar bien el español. Cuando los jesuitas llegaron a Huarochirí, en 1570, ya sería un hombre de 40 años.

Don Gerónimo Cancho Guaman en su rol de testigo a favor de Picoy afirmó que desde su niñez sus padres le habían mantenido al tanto de reuniones entre kurakas importantes y que su padre hasta lo llevó consigo a asistir a encuentros entre la nobleza afiliada a los Ninavilca, hatun kuraka o señores hegemónicos de todo Huarochirí. Aparentemente era normal que los kurakas llevaran a sus hijos, aún niños, a tales reuniones, posiblemente a fin de publicitar su eventual legitimidad como sucesores y para que no se extinguiera la memoria de su derecho durante los interregnos que por rutina se producían mientras los hermanos del difunto señoreaban y rivalizaban. Gerónimo Cancho Guaman se acordó de haber escuchado a los grandes "en las panpas quando se juntaban los yndios en ellas para tratar sus negoçios y en sus huelgas" (f.114v).

El pueblo de Mama figuraba como uno de los lugares de reunión importantes, por su posición geográficamente céntrica como nexo entre los yunka y los serranos de Lurin Yauyos (Huarochirí, Mama, Chaclla), asimismo como por su asociación con su diosa principal, Chaupi Ñamca 'la ñamka [wak'a arcáica?] del centro'. Los testigos dijeron haber aprendido en tales reuniones las genealogías y rangos de las autoridades políticas.

En tales ocasiones, Cancho Guaman aprendió la narrativa dinástica propia a los kurakas afiliados a los Ninavilcas de Huarochirí. Se trata de los datos genealógicamente más profundos hasta ahora conocidos sobre la nobleza Lurin Yauyos. Según los kurakas de Concha y de Checa de San Damián (y no de acuerdo con los testimonios de los señores de Chaclla), existieron durante y después del inkanato, tres linajes de apos, o sea de kurakas supremos, cuya autoridad se extendía sobre múltiples guarangas y pueblos. En cada uno de los tres casos los sandamianinos trazaron la dinastía desde dos generaciones prehispanas. El "apo" ("señor principal') prehispano de Huarochirí, Cocallibia, fue padre de Ninavilca, bautizado Antonio. De éste nació el eminente kuraka colonial Don Sebastián Quispe Ninavilca. El más antiguo "apo" prehispánico de Mama fue Chuquiaca, padre de Anchicarvaya, abuelo de Ticçiguaman, bisabuelo de Don Antonio Guamangualca, y tatarabuelo del litigante Don Antonio Guaman Yañac. Y finalmente el "apo" prehispano de Chaclla, Llacxa Poma, fue padre de Marca Poma, abuelo del kuraka colonial Don Pablo Michui.

Los testimonios esclarecen la diplomacia entre kurakas según fue observada por Cancho Guaman y sus similares a fechas tempranas. En la niñez (o sea, ca. 1530-1545) vieron que "los tres caçiques principales... se sentaban en yguales asientos" (f.108r); es decir que cuando los señores de los pueblos "hijos de Paria Caca" se reunían con su ари Ninavilca, se sentaban sin la manifestación de rango normales para otras reuniones. Los jóvenes testigos, en calidad de hijos de kurakas subalternos de Ninavilca, acompañaban a sus padres cuando éstos viajaban al exterior con embajadas de parte de Ninavilca. Las delegaciones parecen haber sido similares a las misiones mencionadas dentro del famoso pleito de cocales de Quivi (Rostworowski y Marcus 1988) como método utilizado por los Ninavilca. Tales misiones habrían reforzado periódicamente la alianza política llamada de "todos los Yauyos" -formación cuya imagen ideológica influye fuertemente en la mitología del manuscrito anónimo quechua.

En el pleito de Picoy y Yaucha se notan con cierta claridad las funciones de tales delegaciones. En primer lugar, los emisarios renovaban las alianzas mediante intercambios mutuos. Algunos testigos oriundos de Chaclla lo explicaron así:

muchas beçes [el kuraka Ticçi guaman] le enbiaba cachas [hispano-quechuismo: 'mensajeros'] y rrecaudos a marcapoma que en aquel tiempo hera curaca prinçipal en este rrepartimento de chacla y el dicho marca poma: al dicho ticçi guaman (f.114v).

de mama que es cabeza del rrepartimiento bian a los yndios estar aderezando y a juntando camaricos [hispano-quechuismo: 'regalos ceremoniales'] para llebar al dicho guaman (f.115r).

La yuxtaposición de "camaricos" y "recaudos" como cargas de los "cachas" o mensajeros sugiere que la información o documentación ("recaudos") fluía acompañado por los dones simbólicos de la reciprocidad. Es posible que el vehículo de aquellas haya sido el khipu. Se utilizaba la ropa tam- 
bién para señalar las posiciones políticas de las partes:

quando murio el dicho ticçiguaman le suçedio el dicho guamangualca que andaba bestido en auito de español y que para andar camino se bestia como tal y que entre sus yndios andaba con su traje de indio por que ansi lo querian sus yndios (f.109r).

Segundo, en las reuniones en "pampa" se presentaban ocasiones para difundir noticias y arreglar la política colectiva frente a fuerzas externas. Un caso se produjo en el ya mencionado sitio puesto por las fuerzas inkas contra la naciente Ciudad de los Reyes en 1535, cuando ciertos kurakas con intereses en la waranka Mama-incluso los ancestros de las dos partes litigantes en 1588- se sumaron a la defensa de Lima española. Otro ejemplo habría sido la famosa reunión de Mama, de 1562, cuando una asamblea impresionante de kurakas de todo el Perú central acordó con el Padre Domingo Santo Tomás en proponer al Consejo de Indias la extinción de las encomiendas a cambio de un autogobierno indígena con considerable gravamen impositivo (Espinoza Soriano 1983-84:210). A esta reunión habrían asistido Cancho Guaman y Samari como subalternos de Ninavilca, quien dio el apoyo de Huarochirí a la propuesta eventualmente comunicada infructuosamente a España por los dominicos Santo Tomás, Jerónimo de Loayza y Bartolomé de las Casas.

Tercero, las visitas y reuniones "en pampa" servían para fomentar el prestigio del kuraka anfitrión mediante grandiosas redistribuciones de bienes. Los testigos pensaban que en Chaclla colonial Guaman Yañac era considerado un buen kuraka porque "si be algun yndio pobre o que tiene neçesidad aunque no sea de su pueblo le haze dar de comer y le rregala" (f.117v), motivo que hace fuerte eco en el manuscrito anónimo quechua de Huarochirí. En las leyendas repetidamente se enfatiza el trato acordado al pobre wajcha o 'huérfano'que se asoma en el convite, el forastero sin lugar en la jerarquía local.

\section{Conclusiones}

El litigio entre los señores de Yaucha, pertenecientes a un señorío serrano con "islas" enclava- das río abajo cerca del actual Ricardo Palma, y los señores de Picoy, pertenecientes a un señorío yunka con enclaves río arriba por Matucana, proporcionó a Espinoza Soriano un excelente caso para analizar la violenta distorsión de las relaciones entre entidades políticas posibilitada por la irrupción de los españoles y el colapso del Tawantinsuyu. Antes de 1532 se practicaba una alianza triple a nivel macrorregional, basada en el equilibrio de "iguales asientos" kurakales, en la diplomacia articulada por los jatun kuraka Ninavilca de Huarochirí. El balance político dependía mucho de la coordinación ceremonial de los wak'a serranos con los vallunos. Durante la ruptura de 1532-1535 este sistema sufrió abruptos cambios, cuando los hermanos Pomachagua y Condorchagua, señores de Yaucha y khipukamayuq de bienes de la panaka de Tupaq Inka Yupanki, abandonaron el imperio que les había favorecido con sus cargos y hasta con un extenso "archipiélago" de terrenos. Al adquirir ropa exótica, armas europeas y títulos espurios dados por Pizarro, pudieron liderar a quienes pensaban apostar contra los enemigos del Tawantinsuyu. Sus descendientes adquirieron el privilegio injustificado de caciques principales sobre Picoy según deta1la Espinoza Soriano (1983-84).

Más allá de los hechos políticos, los detalles del proceso están vinculados con dos fuentes de suma importancia para el estudio de la cultura andina colonial: la Nueva Corónica de Guaman Poma y el manuscrito anónimo quechua de Huarochirí.

La idealización del nexo entre unidades políticas serranas y vallunas subyace a la mitología inscrita en el anónimo quechua de Huarochirí. Los autores orales de dicha fuente fueron de varias aldeas, y vocearon elementos de varios pactos o ideologías de articulación regional (Rostworowski 1978a), todos básicamente similares, provenientes de la cuenca del río Mala y río Lurín tanto como de la cuenca del Rímac discutido en el litigio de 1588 .

De paso, y para completar el triángulo de fuentes, notamos que durante su viaje por Chorrillos, San Lorenzo [de Quinti] y, especialmente, Sisicaya, Guaman Poma conoció a individuos mencionados por el anónimo quechua. El más relevante al tema de los pactos regionales fue "Don Martín hijo de Don Diego" quién hospedó a Guaman Poma en Sisicaya (1980[1613]:1024). Se trata del hombre que jugó en el Lurín medio un papel paralelo al de 
Cristóbal Choque Casa en el Lurín alto: heredero de kurakazgo, enemigo de los antiguos dioses y adversario de su propio padre en asuntos de culto. El joven Martín Chauca Guamán luchó contra los cultos afiliados a Chaupi Ñamca existentes y aún florecientes en Chillaco y otros lugares del entorno de Sisicaya, cultos, hasta entonces, encubiertos por su padre.

Mientras el recién [fallecido] curaca de Sasicaya, don Diego Chaucaguamán, vivía, los chillaco y otra gente también celebraba su fiesta [y eso] duró hasta la llegada de don Martín (Taylor 1987: 226-227).

Volviendo al tema de las luchas en el valle del Rímac: Los checa serranos de Huarochirí central (notablemente los habitantes de la reducción de San Damián) resultaron testigos interesados en la lucha entre Picoy y Yaucha, porque su "isla" subtropical en Suquia Cancha formó enclave dentro de las tierras de Picoy y la reducción de Surco. Al estudiar los testimonios de los Sandamianinos Gerónimo Cancho Guaman y Domingo Samari, llegamos a ver más de cerca cómo funcionaba el pacto regional que regía el acceso a los preciosos terrenos de las riberas del Rímac medio. El valor del litigio para el estudio de la mitología huarochirana consiste en el contexto político que surge, complementando el enfoque sacerdotal y ritualista del texto quechua. Al saber que Gerónimo Cancho Guaman formaba parte de la alianza que sostenía los intereses de Picoy, sobre todo durante los disturbios y usurpaciones ocasionados por la invasión española, llegamos a entender que su defensa o encubrimiento de los cultos no sólo de Llocllay Huancupa, sino de todas las diosas de los valles, formó parte integral del modus vivendi que permitió la participación multiétnica en recursos de yunka subtropical.

Cuando vemos a Guaman Poma, otra vez obtenemos del litigio un trasfondo político, esclarecedor de representaciones al parecer clásicamente prehispanas. Para Guaman Poma, los dos hombres que por excelencia encarnaron el arte del khipu bajo el inkario fueron Condor Chaua y Poma Chaua, homónimos exactos de los contrincantes yauchas del conflicto en el Rímac y a nuestro juicio los mismos individuos. Guaman Poma los dibuja en atuendos enteramente inkas y en contexto de espacios ceremoniales inkas. Sin embargo en otros con- textos, como el poema descrito anteriormente y en un comentario sobre el alzamiento de "Mango Ynga" (Guaman Poma 1980[1613]:371) coloca a Condor Chaua y a Poma Chaua en contextos post1532. Es muy conocida la preferencia del "autor y príncipe" por los linajes asociados con "Yarovilca Allauca Huánuco". "Yaro," una vez sinónimo de Paria Caca, connota una región no lejana al escenario huarochirano, además se sabe que Guaman Poma transitó Huarochirí y menciona repetidamente a sus kurakas los Ninavilca.

Parece creíble que los dos íconos del khipu prehispano, el "CONTADOR MAYOR I TEZORERO TAVANTINSVIO QUIPOC CVRACA CONDOR CHAVA" y el "administrador suyuyoc apo poma chaua", hayan sido en realidad hombres de la generación capacitada antes de 1532 y destinados a participar en la transformación colonial. Hijos de una nobleza étnica no muy distante de los ancestros de Guaman Poma, es posible que fueran conocidos del cronista huamanguino. Sospecho que Guaman Poma escogió dos khipukamayuq politiqueros de la alborada de la colonia, e idealizó su anterior función como custodios de bienes de panaka, elevándolos ficticiamente en arquetipos de la cúpula inka. La influencia de los hermanos Pomachaua y Condorchaua, posiblemente se refleja en el hecho de que Guaman Poma describió al "DECIMO INGA TOPA INGA IVPANGQUI", cuya momia estuvo a cargo de los hermanos Pomachaua y Condorchaua, como el soberano que perfeccionó la aplicación administrativa de los khipu (1980 [1613:91). Si la relación en efecto fue así, la información sobre el arte de los khipus derivada de estos dibujos proviene de prácticas tardías del Inka y todavía vigentes en la colonia temprana. Dicha información debe ser aplicable, pues, al análisis de los khipus coloniales que tanto han influido en la etnohistoria. Igualmente sospechamos que la yupana $\mathrm{o}$ tabla de fichas que asoma al lado del "contador mayor" pertenece a la misma práctica descrita en el proceso, porque tiene similitud con el procedimiento descrito por Dávila Brizeño en su informe sobre la averiguación con nobles de Yaucha. Esta correspondencia interesa porque demuestra la mediatización del khipu con piedras en asuntos que no fueron de contabilidad, sino de genealogía o historia.

¿El oficio de khipukamayuq imperial habrá contribuido a la capacidad de los hermanos yauchas para conquistar nuevos poderes durante la transi- 
ción al virreinato? Queda bien documentado el hecho de que en todas partes ciertos kurakas pudieron sacar ventaja de la conyuntura colonial inicial (p. ej. Oberem 1967; Powers 1990; Spalding 1974:31-87) con o sin khipu. Sin embargo, el cargo de administrador de bienes del difunto Inka -pertenencias de una panaka- habrá ofrecido un recurso adicional a los dos kurakas ya adiestrados en el teje-y-maneje de la política regional. En varias partes del Perú, la contabilidad andina demostró una vitalidad impresionante. Mientras muchas instituciones andinas se derrumbaban bajo las presiones de guerra, reducción, extirpación, mita y epidemias, el uso de los khipu se mantuvo durante el siglo XVI como un sostén principal para reivindicar los intereses andinos en propiedades y otros derechos o articular el nexo con la encomienda (Loza 1998; Pease 1990; Sempat 2002). En la administración interna de las comunidades duró mucho más (Salomon 2002; Salomon y Spalding 2002).

Al finalizar la lectura del pleito Yaucha-Picoy (y varios similares), da la impresión de que las fuentes narrativas básicas referentes a la etapa final del
Tawantinsuyu y al inicio de la colonia se conectan por más contactos personales, más noticias compartidas, más alianzas y más fuentes comunes de lo que sus respectivos autores explican. Bien vale la pena, por lo tanto, seguir los contactos a través de procesos jurídicos. Los testimonios de autores y testigos coetáneos durante la época toledana sugieren la existencia no sólo de individuos en posesión de importantes datos etnohistóricos, sino de una comunidad de discurso crítico dedicada a repensar lo precolombino, ya entre la primera generación de "los hombres llamados indios" (Taylor 1987:40-41).

Agradecimientos: Se agradece cordialmente la ayuda de Lorena Toledo al hacer la transcripción paleográfica y el apoyo de las entidades que posibilitaron el presente estudio: Instituto de Estudios Peruanos, National Endowment for the Humanities, National Science Foundation, Wenner-Gren Foundation, John Simon Guggenheim Memorial Foundation, School of American Research y The Graduate School of the University of Wisconsin.

\section{Documentos Manuscritos Citados}

Archivo General de Indias / Sevilla

1548 Audiencia de Lima 121. Título de la encomienda del repartimiento de Huarochirí dado por el presidente La Gasca a Geronimo de Sylba. 2 f.
Archivo General de la Nación / Buenos Aires 1588-90 (ms. 9-45-5-15) Pleito segundo entre Antonio Guamanyanac y Geronimo Caxayauri 1588. 158 f.

\section{Referencias Citadas}

Acosta Rodríguez, A.

1987 Francisco de Ávila Cusco 1573(?) - Lima 1647. En Ritos y Tradiciones de Huarochirí del Siglo XVII, editado y traducido por G. Taylor, pp. 551-616. Instituto de Estudios Peruanos/Instituto Francés de Estudios Andinos, Lima.

Amat Olazábal, $\mathrm{H}$

1992 Los yaros en la historia de Huarochirí. En Huarochirí, Ocho Mil Años de Historia, editado por Vladimiro Thatar Álvarez, pp. 67-16. Municipalidad de Santa Eulalia de Acopaya, Santa Eulalia.

Ascher, M. y R. Ascher

1997 [1981] Code of the Quipu: A Study of Media, Mathematics, and Culture. Dover Publications, New York.

Arguedas, J.M. y P. Duviols

1966 Dioses y Hombres de Huarochirí, traducido por J.M. Arguedas con estudio de P. Duviols. Instituto de Estudios Peruanos y Museo Nacional de Historia, Lima.

Dávila Brizeño, D.

1965 [1583] Descripción y relación de la provincia de los
Yauyos. En Relaciones Geográficas de Indias, editado por M. Jiménez de la Espada, T.1. pp. 155-65. Ediciones Atlas, Madrid.

Espinoza Soriano, W.

1983-84 Los señoríos de Yaucha y Picoy en el abra del medio y alto Rímac (siglos XV y XVI). Revista Histórica 34:157-279.

Guaman Poma de Ayala, F.

1980 [1613] Nueva Corónica y Buen Gobierno del Perú, editado por John V. Murra y Rolena Adorno, con traducciones de Jorge L. Urioste. 3 vols. Siglo XXI, México D.F. 1991 [1595] Y No Hay Remedio, editado por E. Prado Tello y A. Prado Prado. CIPA, Lima.

Loza, C.B.

1998 Du bon usage des quipus face à l'administration coloniale espagnole (1500-1600). Population 1-2:139-160.

Oberem, U.

1967 Don Sancho Hacho, ein cacique mayor des 16. Jahrhunderts. Jahrbuch für Geschichte von Staat, Wirtschaft und Gesellschaft 4:199-225. 
Murra, J. V.

1975 [1972] El control vertical de un máximo de pisos ecológicos en la economía de las sociedades andinas. En Formaciones Económicas y Políticas del Mundo Andino, pp. 59-116. Instituto de Estudios Peruanos, Lima.

Pease, $\mathrm{F}$

1990 Utilización de quipus en los primeros tiempos coloniales. En Quipu y Yupana. Colección de Escritos, editado por C. Mackey, pp. 67-72. CONCYTEC, Lima.

Platt, T.

2002 "Without deceit or lies". Variable chinu readings during a sixteenth-century tribute-restitution trial. En Narrative Threads: Accounting and Recounting in Andean Khipu, editado por J. Quilter y G. Urton, pp. 225-265. University of Texas Press, Austin.

\section{Powers, K.M.}

1990 Los caciques intrusos, migraciones y cambios sociopolíticos en la Audiencia de Quito. Actas do Congreso sobre a História da População da América Latina, pp. 33-38. Fundação SEADE, São Paulo.

Quilter, J. y G. Urton, eds.

2002 Narrative Threads: Accounting and Recounting in Andean Khipu. University of Texas Press, Austin.

Radicati di Primeglio, C.

1965 La "seriación" como posible clave para descifrar los quipus extranumerales. Documenta, Revista de la Biblioteca Nacional 4:112-196.

Rostworowski, M.

1960 Succession, co-option to kingship, and royal incest among the Inca. Southwestern Journal of Anthropology 16: 417-427.

1978a El avance de los Yauyos hacia la costa en tiempos míticos. En Señoríos Indígenas de Lima y Canta, pp. 31-44. Instituto de Estudios Peruanos, Lima.

1978b Los Yauyos coloniales y el nexo con el mito. En Señoríos Indígenas de Lima y Canta, pp.109-122. Instituto de Estudios Peruanos, Lima.

Rostworowski, M. y J. Marcus

1988 Conflicts over Coca Fields in XVIth-Century Peru.
Museum of Anthropology, University of Michigan, Ann Arbor.

Rowe, J.H.

1945 Absolute Chronology in the Andean Area. American Anthropologist 10:265-284.

Salomon, F.

2002 Patrimonial khipus in a modern peruvian village: An introduction to the "quipocamayos" of Tupicocha, Huarochirí. En Narrative Threads: Explorations of Narrativity in Andean Khipus, editado por J. Quilter y G. Urton, pp. 293-319. University of Texas Press, Austin.

Salomon, F. y K Spalding

2002 Cartas atadas con khipus: Sebastián Franco de Melo, María Micaela Chinchano, y la represión del levantamiento huarochirano de 1750. En El Hombre y los Andes. Homenaje a Franklin Pease G., editado por J. Flores Espinoza y R. Varón Gabai, pp. 857-870. Fondo Editorial de la Pontificia Universidad Católica del Perú, Lima.

Sempat Assadourian, C.

2002 String registries: native accounting and memory according to the colonial sources. En Narrative Threads: Accounting and Recounting in Andean Khipu, editado por J. Quilter y G. Urton, pp. 119-150. University of Texas Press, Austin.

Spalding, K.

1974 De Indio a Campesino. Cambios en la Estructura Social del Perú Colonial. Instituto de Estudios Peruanos, Lima.

Stern, S. J

1982 Peru's Indian Peoples and the Challenge of Spanish Conquest. Huamanga to 1640. University of Wisconsin Press, Madison.

Taylor, G.

1987 Ritos y Tradiciones de Huarochirí del Siglo XVII, traducido y editado por G. Taylor con ensayo de A. Acosta. Instituto de Estudios Peruanos/Instituto Francés de Estudios Andinos, Lima.

Urton, G.

2002 Codificación binaria en los khipus incaicos. Revista Andina 35:9-68. 